\title{
Proteomic analysis of rat cerebral cortex, hippocampus and striatum after exposure to morphine
}

\author{
ANNA BIERCZYNSKA-KRZYSIK ${ }^{1,2}$, JULIUS PAUL PRADEEP JOHN ${ }^{2}$, JERZY SILBERRING $^{1}$, \\ JOLANTA KOTLINSKA ${ }^{3}$, TOMASZ DYLAG ${ }^{1}$, MAUREEN CABATIC $^{2}$ and GERT LUBEC ${ }^{2}$ \\ ${ }^{1}$ Department of Chemistry, Neurobiochemistry Unit, Jagiellonian University, Krakow, Poland; ${ }^{2}$ Department of Pediatrics, \\ Medical University of Vienna, Vienna, Austria; ${ }^{3}$ Department of Pharmacokinetics, Medical Academy, Lublin, Poland
}

Received March 21, 2006; Accepted May 30, 2006

\begin{abstract}
Although a series of proteins in the brain have been shown to be qualitatively or quantitatively dysregulated following morphine administration, a systematic proteomic study has not been carried out so far. We therefore aimed to show the effect of morphine on protein levels in the rat brain. For this purpose rats were given a morphine base in subcutaneously placed pellets and subsequently the cerebral cortex, hippocampus and striatum were taken for proteomic studies after three days. Extracted proteins were run on twodimensional gel electrophoresis, scanned and quantified by specific software. Proteins with significantly different levels were analysed by mass spectrometry (MALDI-TOF-TOF). Twenty-six proteins were found to be differentially expressed and were unambiguously identified. Dysregulated proteins were from several protein pathways and cascades including signaling, metabolic, protein handling, antioxidant and miscellaneous classes. These findings represent an initial approach to the generation of a 'morphinome' and may form the basis for further protein chemical studies as a valuable analytical tool. Moreover, the study reveals morphine-regulated proteins in different brain areas and indicates the pathways involved following morphine administration in the rat, the main species for pharmacological studies in the field.
\end{abstract}

\section{Introduction}

In 1969 Oswald (1) began addressing human brain proteins, drugs and dreams, while Mackler and Eberwise subsequently approached this problem at the transcriptional level (2). In this review the authors show addictive drug-induced changes in gene expression and indicate the need for research into the area.

Correspondence to: Professor Gert Lubec, Medical University of Vienna, Department of Pediatrics, Währinger Gürtel 18, A-1090 Vienna, Austria

E-mail: gert.lubec@meduniwien.ac.at

Key words: cerebral cortex, hippocampus, striatum, morphine
In a more specific review, Harlan and Garcia have focused on the effects of drug abuse on immediate early genes in the forebrain addressing the importance of individual areas and discussed the possible biological significance of these transcripts (3). Torres and Horowitz (4) summarized reports on activation of signal transduction pathways that in turn regulate gene expression in the brain. Morphine-induced changes of gene expression in the brain have been recently reviewed by Ammon-Treiber and Hollt (5) who reported on gene expression profile studies of morphine-responsive genes, influences on metabolism, chaperones, transcription factors and the protein synthetising machinery and major receptor systems. Jacobs and coworkers finally contributed the dimensions of regional and temporal specificity of drug-induced gene expressional changes at the gene level (6). Only recently Kim and coworkers (7) carried out a proteomic systematic study on phosphotyrosyl proteins in morphine-dependent rat brains.

A more general systematic approach to carry out protein hunting in control versus morphine-treated rat brain areas has not yet been performed and this formed the rationale for our studies. We aimed to differentiate between brain protein levels in three areas known to be affected by morphine treatment in the rat, using well-established proteomic methodology (8-12) involving two-dimensional gel electrophoresis, quantification of protein spots and unambiguous identification of protein spots by MALDI-TOF-TOF. A series of dysregulated structures was observed and new morphine-responsive proteins were revealed and some changes obtained at the transcriptional level were confirmed at the protein level.

\section{Materials and methods}

Animals and treatment. Male Wistar rats obtained from a local distributor (HZL, Warsaw, Poland), weighing 150-200 g were used in the experiments. Animals were housed in groups of five per cage, under a 12/12-h light/dark cycle in an airconditioned room. Water and standard food (Bacutil, Motycz, Poland) were freely available to the housed rats. Morphine dependence was induced by subcutaneous implantation of pellets containing $75 \mathrm{mg}$ of morphine base, according to the modified procedure reviewed in ref. 13. Pellets were implanted in the animals' necks under light ether anaesthesia. Control animals received placebo (physiological saline $0.9 \% \mathrm{NaCl}$ ) instead of morphine. 
Ethical requirements. All experiments were performed in agreement with the respective Polish and European Communities Council Directives (86/609/EEC), and were approved by the local ethics committee (permission no. 367/2002).

Tissue excision. Animals were sacrificed by decapitation 3 days after implantation of pellets. Brains were removed and placed on a dry ice cooled plate. Cerebral cortex, hippocampus and striatum were taken and verified by histology. Pairs of each kind of tissue were placed in Eppendorf tubes (Eppendorf, Hamburg, Germany) and immediately frozen on dried ice. Tissues were stored at $-80^{\circ} \mathrm{C}$.

Two-dimensional gel electrophoresis. In total, six striata, six hippocampi and six cerebral cortex tissues dissected from control rats were subjected to 2-D gel electrophoresis. The same amount of material obtained from morphine exposed animals was processed.

Tissues were powderized in liquid nitrogen and suspended in $1 \mathrm{ml}$ of sample buffer consisting of $7 \mathrm{M}$ urea, $2 \mathrm{M}$ thiourea, 4\% CHAPS, $10 \mathrm{mM}$ dithiothreitol (DTT), $1 \mathrm{mM}$ EDTA, $1 \mathrm{mM}$ phenylmethylsulfonyl fluoride (PMSF) and a mixture of protease inhibitors (Roche Diagnostics, Mannheim, Germany). When sonicated $(5 \times 4 \mathrm{sec})$, the suspension was left at room temperature for $1 \mathrm{~h}$ and centrifuged at $14,000 \mathrm{x} \mathrm{g}$ and $120^{\circ} \mathrm{C}$ for $60 \mathrm{~min}$. Ultrafree-4 centrifugal filter units (Millipore, Bedford, MA, USA) were used for sample desalting. Protein content was determined by the Bradford method. 2-DE was performed essentially as reported by Yang et al (9). Approximately $0.8 \mathrm{mg}$ protein was applied on immobilized $\mathrm{pH}$ 3-10 nonlinear gradient strips. Focusing was started at $200 \mathrm{~V}$ and the voltage was gradually increased to $8000 \mathrm{~V}$ at $4 \mathrm{~V} / \mathrm{min}$ and kept constant for $3 \mathrm{~h}$ (approximately 150,000 V/h in total). After the first dimension, strips $(13 \mathrm{~cm})$ were equilibrated for $15 \mathrm{~min}$ in the buffer containing $6 \mathrm{M}$ urea, 20\% glycerol, $2 \% \mathrm{SDS}, 2 \%$ DTT and then for $15 \mathrm{~min}$ in the same buffer containing $2.5 \%$ iodoacetamide instead of DTT. The seconddimensional separation was performed on $9-16 \%$ gradient sodium dodecyl sulfate (SDS) polyacrylamide gels. The gels $(180 \times 200 \times 1.5 \mathrm{~mm})$ were run at $40 \mathrm{~mA}$ per gel. Once fixated in $50 \%$ methanol and $10 \%$ acetic acid for $12 \mathrm{~h}$, the gels were stained with colloidal Coomassie blue (Novex, San Diego, CA, USA) for $8 \mathrm{~h}$. Molecular masses were determined by running standard protein markers (Bio-Rad Laboratories, Hercules, CA, USA) covering the range $10-250 \mathrm{kDa}$. pI values were used as given by the supplier of the immobilized $\mathrm{pH}$ gradient strips (Amersham Bioscience, Uppsala, Sweden). Excess dye was washed from the gels with distilled water. Next, gels were scanned with Image Scanner (Amersham Biosciences, Piscataway, NJ, USA).

Statistical gel image analysis and protein quantification. Proteomweaver software (version 3.0, Definiens AG, Munich, Germany) was used for gel image analysis and protein quantification. In total 36 gels, twelve gels for each brain structure, six for the control and six for the morphine group, were examined. All well resolved spots were analyzed and quantified. Student's t significance of regulation was used to determine the differentially expressed proteins. The level of significance was set at $\mathrm{P}<0.05$.
In-gel digestion of proteins, MALDI-TOF and MALDI-TOF/ TOF mass spectrometry. Visualized spots representing differentially expressed proteins were picked from the gels and prepared for matrix-assisted laser desorption/ionization mass spectrometrical analysis.

Spots were excised with a spot picker (PROTEINEER $\mathrm{sp}^{\mathrm{TM}}$, Bruker Daltonics, Leipzig, Germany) and placed into 96-well microtiter plates. Then in-gel digestion and sample preparation were performed by an automated procedure (PROTEINEER $\mathrm{dp}^{\mathrm{TM}}$, Bruker Daltonics) (14). Briefly, all selected spots were excised and washed with $10 \mathrm{mM}$ ammonium bicarbonate and $50 \%$ acetonitrile in $10 \mathrm{mM}$ ammonium bicarbonate. Next, gel plugs were shrunk by addition of acetonitrile and dried by blowing out the liquid through the pierced well bottom. The dried gel pieces were reswollen with $40 \mathrm{ng} / \mu 1$ trypsin (Promega, Wisconsin, USA) in enzyme buffer (containing $5 \mathrm{mM}$ Octyl ß-D-glucopyranoside (OGP) and $10 \mathrm{mM}$ ammonium bicarbonate) and incubated for $4 \mathrm{~h}$ at $30^{\circ} \mathrm{C} ; 10 \mu \mathrm{l}$ of $1 \%$ TFA in $5 \mathrm{mM}$ OGP served for peptide extraction. Extracted peptides were directly applied onto a target (AnchorChip ${ }^{\mathrm{TM}}$, Bruker Daltonics) loaded with $\alpha$-cyano-4-hydroxy-cinnamic acid (CHCA) (Bruker Daltonics) matrix thinlayer. Ultraflex ${ }^{\mathrm{TM}}$ TOF/TOF (Bruker Daltonics) used for mass spectrometrical analysis operated in the reflector for MALDI-TOF peptide mass fingerprint (PMF) and LIFT mode for MALDI-TOF/TOF using FlexControl ${ }^{\mathrm{TM}}$ software. An accelerating voltage of $25 \mathrm{kV}$ was used for PMF. $[\mathrm{M}+\mathrm{H}]^{+}$ions of angiotensin I, angiotensin II, substance P, bombesin, and adrenocorticotropic hormones (clip 1-17 and clip 18-39), were used for external calibration of the instrument. At least 200 consecutive laser shots were accumulated in order to produce one spectrum. Samples analyzed by PMF from MALDI-TOF were additionally analyzed using LIFTTOF/TOF MS/MS. For several protein spots, automatic analysis did not provide satisfactory results (f.ex. low score, lack of MS/MS data) and manual spectra acquisition was also performed. In the TOF1 stage, all ions were accelerated to $8 \mathrm{kV}$ under conditions promoting metastable fragmentation. Once jointly migrating parent and fragment ions were selected in a timed ion gate, ions were lifted by $19 \mathrm{kV}$ to high potential energy in the LIFT cell. PMF and LIFT spectra were interpreted using the MASCOT search engine (Matrix Science, London, UK). Database searches, through Mascot, using combined PMF and MS/MS datasets were performed via BioTools 2.2 software (Bruker). A mass tolerance of $25 \mathrm{ppm}$, 1 missing cleavage site for PMF and MS/MS tolerance of $0.5 \mathrm{Da}$ and 1 missing cleavage site for MS/MS search were allowed, carbamidomethylation of cysteine and oxidation of methionine residues were considered. Since human and mouse genomes are better annotated than rats' and more protein sequences are included in the databases, a wider taxonomy setting was used while performing database search.

The probability score calculated by the software was used as criterion for correct identification. The algorithm used for determining the probability of a false positive match with a given mass spectrum is described elsewhere (15).

\section{Results}

Quantitative analysis of two-dimensional gel sets, performed for cerebral cortex, hippocampus and striatum of morphine 
administered rats and controls, resulted in identification of morphine-dependent protein expression. Six gels from controls were compared to six gels from rats with morphine. In total, 36 gels were analyzed with Proteomweaver ${ }^{\circledR}$ controlled by manual inspection. The average number of protein spots on gels was approximately 1000 . Spots that were well-separated to enable quantification were analyzed by mass spectrometry. The Student's t-test was applied for comparing groups and a level of $\mathrm{P}<0.05$ was considered significant. Twenty-seven protein spots: 8 from the cerebral cortex, 5 from the hippocampus and 14 from the striatum were shown to be significantly different between the morphine-treated and the control group. Mass spectrometrical analysis resulted in identification of 26 distinct proteins. In the protein pattern obtained from hippocampus two isoforms of Lon protease were observed.

Table I represents a complete list of identified proteins, including details of quantification and MS analysis. Supplementary Table II includes a brief description of the known functions of the proteins observed. Supplementary Figs. 1-6 present differentiated protein spots in the cerebral cortex (Figs. 1-2), hippocampus (Figs. 3-4) and striatum (Figs. 5-6).

\section{Discussion}

\section{Cerebral cortex}

Proteins with abundance higher than in morphine-treated rats. The protein similar to isoform of WD-repeat protein 1 is a member of the family of WD proteins, consisting of highly conserved repeats usually ending with Tryp-Asp(WD) and implicated in a variety of cellular functions including transmembrane signalling, transcription, cell division, cell-fate determination, vesicle fusion and apoptosis (16). Among other functions, WD family members are related to signalling pathways as e.g. the PKC system (17) that in turn has been shown to be dysregulated by morphine-administration. A translocase of outer mitochondrial membrane 70 homolog A (TOM70) contains the tetratricopeptide (TPR) motif that in turn plays a role in cell-cycle regulation, transcriptional repression, the stress response, protein folding, protein kinase inhibition, neurogenesis, mitochondrial and peroxisomal transport (18). Aberrant expression of this protein may therefore represent or lead to mitochondrial or peroxisomal damage in morphine-induced brain damage and aberrant levels of TOM70 were shown in brains of a dementing neurodegenerative disease with mitochondrial damage.

Proteins with abundance lower than in morphine-treated rats. A number of metabolic enzymes including those from glycolysis, citric acid cycle, energy metabolism, the respiratory chain, and amino acid metabolism were shown to be morphinedependently regulated in the rat. Malate dehydrogenase 2 is the only protein revealing significantly increased phosphorylation in morphine-treated animals (7). Cytosolic malate dehydrogenase, a member of the citric acid cycle catalysing the interconversion from malate to oxaloacetate was relatively increased in the rat exposed to morphine (19). This is in agreement with our finding and may suggest modulation of the intermediary metabolism by morphine administration, although the biological consequence remains elusive. Deranged levels of 4-aminobutyrate aminotransferase (GABA aminotransferase), however, may be of particular interest as they are known as a main component of the GABA shunt. In chronic morphine exposure Prokai described down-regulation of this structure in rat forebrain (19). Vinnitskaia and coworkers reported that morphine administration led to decreased cortical GABA and glycine levels that may help to explain morphine's excitatory effects (20). Furthermore, opiate reinforcement has been proposed to be mediated by inhibition of mesolimbic GABA release that in turn stimulates ventral tegmental area dopaminergic neurons (21). The aldo-keto reductase family 7 (herein represented by member A2, AKR7a2) includes a number of $\mathrm{K}^{+}$ion channel $B$ chain regulatory domains and a number of related monomeric NADPH-dependent oxidoreductases. The AKR7 sub-family is able to catalyse reduction of toxic aldehydes, including $\alpha$-unsaturated carbonyl compounds, to alcohols (22). When morphine leads to mitochondrial damage, generation of toxic aldehydes may be expected and increased AKR7a2 expression may serve for detoxification of these products. The role of the A2 protein in morphine-dependent mechanisms has not been addressed so far but members of the AKR family are constitutively associated with protein kinase $\mathrm{C}$ displaying 25 PKC consensus phosphorylation sites indicating modulation of a major signaling system. Cytochrome c oxidase is a component of the respiratory chain complex and major player in the mitochondrial redox system. Decreased levels in morphine-treated rats may be seen in the light of the nitric oxide system: Morphine-induced NO release causes partial inhibition of the respiratory chain function at the level of cytochrome c oxidase $(7,23)$. This in turn is consistent with morphine effects on mitochondrial function. Reduction of ATP synthase $\beta$ chain levels may represent impairment of energy production by morphine: this compound was already proposed to decrease ATP levels as well as the energy charge potential (24) and ATP synthase $\beta$ chain precursor was already detected among phosphotyrosyl-proteins in morphinedependent rats (7). Phosphatidylethanolamine-binding protein (PEBP) has been reported as a 23-kDa morphine-binding protein (synonym; HCNPpp) binding ATP, opioids and phosphoethanolamine and increasing production of choline acetyltransferase. Moreover, it binds lipids, interacts with membrane signaling machinery and functions as a precursor protein of bioactive brain neuropeptides, hippocampal cholinergic neurostimulating peptide (HCNP) and Raf kinase inhibitor protein $(25,26)$. Down-regulation of PEBP has been described to result in altered coordination of signal transduction pathways contributing to neuronal dysfunction in patients with Alzheimer's disease. A single administration of morphine led to a significant decline in choline acetyltransferase activity in several brain areas probably linking PEBP with cholinergic impairment (27).

\section{Hippocampus}

Proteins with higher abundance in morphine-treated rats. Heat shock cognate 71-kDa protein (HSC70) is a key element of the chaperone machinery and functions in folding and refolding in an ATP-dependent manner (28). Higher steady state levels of HSC70 in morphine-treated rats may be a consequence of morphine-induced impaired glucose homeostasis and 


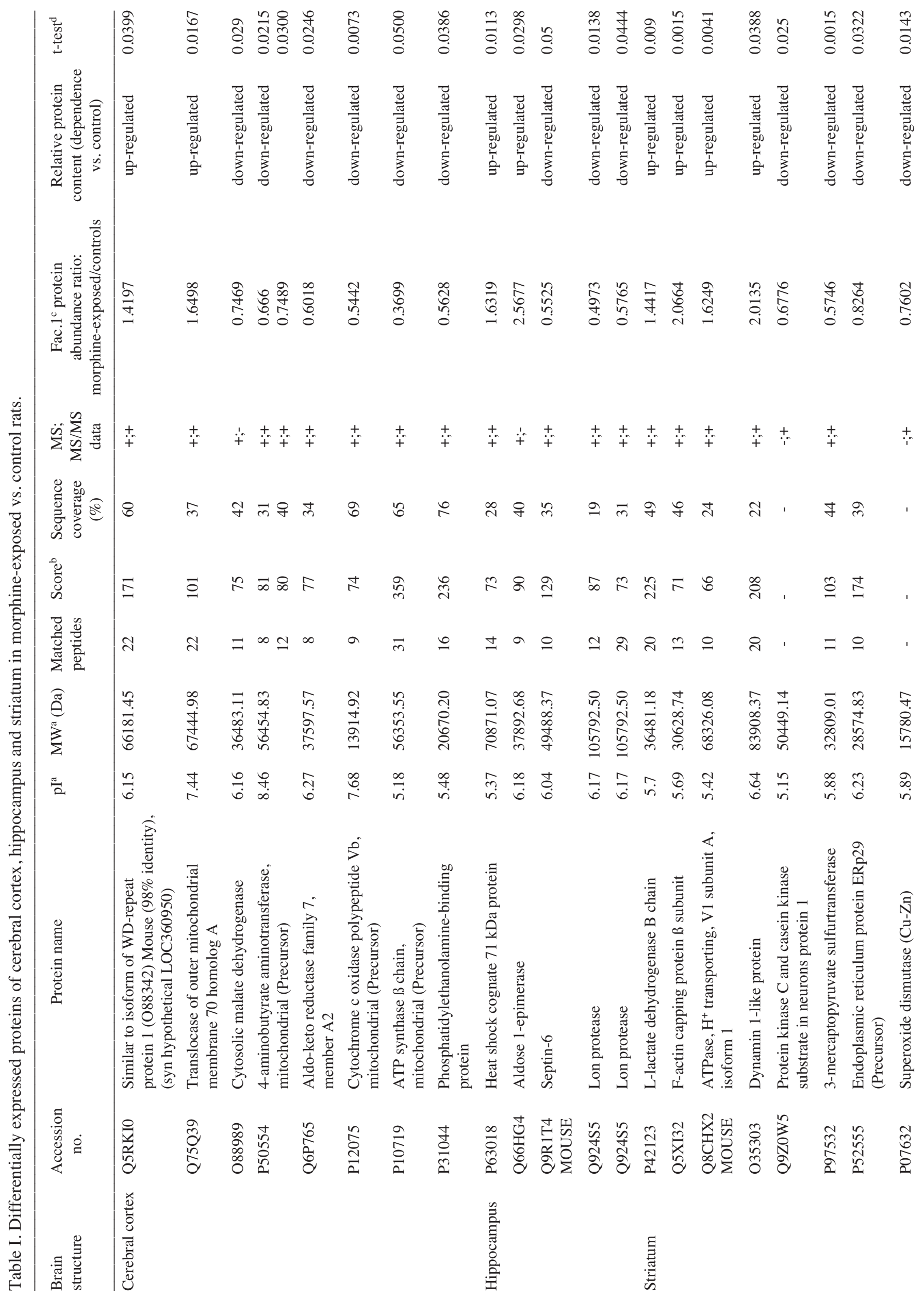




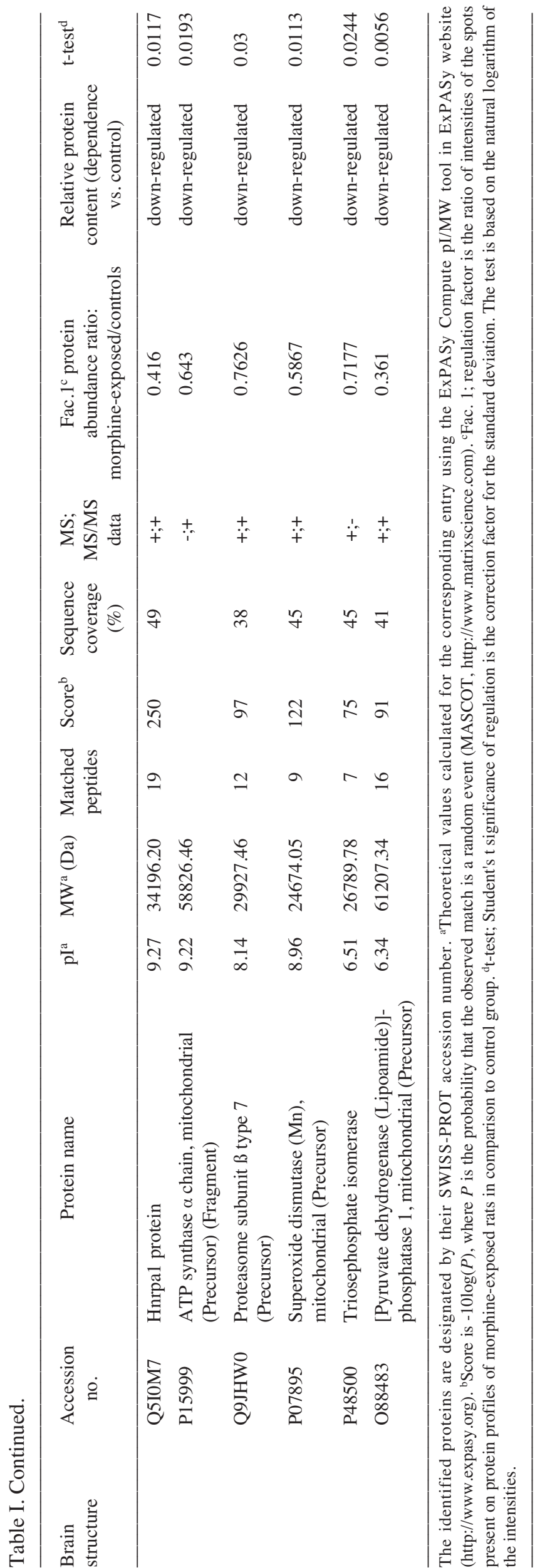

metabolism (29). Aldose 1-epimerase (syn: mutarotase) is a key enzyme of carbohydrate handling catalysing the interconversion of $\alpha$-aldolase to the $\beta$ anomer of glucose and galactose. Although no direct link between opioid and insulin signaling has been defined, Li et al (29) demonstrated disruption of functional signaling complexes by morphine.

Both altered protein levels pointed to modulation of carbohydrate metabolism following morphine administration although there is no explanation why this fact was not reflected in all three brain areas examined. However, it is welldocumented that morphine and other drugs specifically affect individual brain regions only $(30,31)$

Proteins with lower abundance in morphine-treated rats. In addition to morphine-induced mitochondrial protein deficits as shown above and below a major regulator of multiple mitochondrial functions, Lon protease, was down-regulated in morphine-treated hippocampus. It acts as a protease and a chaperone and promotes assembly of cytochrome c oxidase subunits. Dysregulation of this structure may lead to apoptosis by caspase 3 activation (32) and induction of apoptosis by morphine is a well-documented effect (33). Although mechanisms of neuronal apoptosis, following morphine administration, remains unclear, one may propose mitochondrial deficits as a mechanism to be taken into consideration (34).

\section{Striatum}

Proteins with higher abundance in morphine-treated rats. Changes of metabolic elements were also observed in this brain region: increased L-lactate dehydrogenase catalysing conversion of L-lactate to pyruvate, the last step in anaerobic glycolysis again may contribute to metabolic changes following morphine administration.

The V1 subunit of $\mathrm{H}^{+}$transporting ATPase is responsible for acidification of a variety of intracellular compartments in eukaryotes. Up-regulation of this protein was observed in rat forebrain after chronic morphine administration and we report this effect in the acute phase (19). Kim and coworkers reported increased tyrosine phosphorylation in morphine-dependent rat brain that would indicate increased levels and increased activation of this ATPase probably reflecting or leading to altered acid-base balance (7). This is in agreement with the results of Ela and coworkers showing that morphine leads to induction of acidosis in cardiomyocytes (35).

Morphine-induced cytoskeleton changes were also revealed herein: $F$-actin capping protein, $\beta$ subunit, is crucial for cellular and organelle movements and regulating several transport systems (36), a function shared with dynamins. Dynamin 1like protein is a member of the dynamin family that in turn belongs to the G-protein superfamily clan. Both, GTPase and $\mathrm{PH}$ domains of the family may determine the basic functions. Information on the protein is limited and we cannot assign a clear function.

Derangement of dynamin 1-like levels by morphine may be seen in the context of the morphine-mediated cytoskeleton changes reported by Ziolkowska and coworkers (37).

Proteins with lower abundance in morphine-treated rats. Metabolic alterations known to occur by morphine administration were also reflected in this area. 3-mercaptopyruvate 
sulfurtransferase catalyses the transfer of a sulfur ion to cyanide or other thiol compounds and serves for thiosulfate biosynthesis. One may speculate that this enzyme is involved in the morphine-induced alteration of the redox system (Bhat). Both common forms of superoxide dismutase (SOD) catalysing the dismutation of superoxide into molecular oxygen and hydrogen peroxide were down-regulated in striatum of morphine-treated rats. It is not clear whether down-regulation of SODs plays a pathogenetic role for neuronal apoptosis in morphine but mitochondrial deficits may very well lead to increased active oxygen species. The report that oxidative stress is observed in heroin abuse does not answer the question of whether it is causative or simply a consequence of cell death (38). The redox imbalance due to the mitochondrial deficit, however, may point to the generation of active oxygen species but it is currently not clear why SODs show reduced levels and we may only conclude that these enzymes are under morphine control.

In contrast, reduction of the $\alpha$ isoform of ATP synthase is in agreement with previous work showing that morphine alters the energy metabolism (24) and triosephosphate isomerase is also a key enzyme in energy metabolism $(39,40)$. The reduction in its levels may be seen in the context of morphine-induced impaired energy metabolism.

The reduction of Endoplasmic reticulum protein Erp29 levels may be relevant for protein misfolding as Erp29 is considered a chaperon (41). Dysregulation of chaperones has been described previously at the mRNA level and herein we reveal morphine-dependent regulation of Erp29 with probable consequences on folding of secreted proteins in the EPR (42).

Protein handling may be deranged as well as a proteasome element and a heterogeneous nuclear ribonucleoprotein were dysregulated. Proteasome subunit $\beta$ type 7 was decreased in the striatum of morphine-treated animals and indeed the proteasome system is affected by this drug. Mouledous (43) proposed that the ubiquitin-proteasome pathway plays a role in altering the neuronal balance of heterotrimeric G-proteins and adenylate cyclases and is therefore evoking dependence during long-term administration of opiates.

At least, the disturbed concerted action, e.g. altered stoichiometry of this proteolytic system, could be modulating protein handling in general and likewise, changing levels of heterogeneous nuclear ribonucleoprotein Al may be interfering with physiological protein handling probably also by interaction with neuroprotective apoE (36).

Neuroadaptive changes in signal transduction following opioid exposure are mediated by protein kinase(s) C. It is a signaling structure known to be involved in the development of cellular and molecular adaptation to opioid exposure and mediates phosphorylation of opioid receptor proteins, their corresponding G-proteins and several related effector proteins resulting into opioid receptor desensitization (44). Li observed enhanced PKC activity with decreased protein levels in spinal cord cytosol and membrane fractions following morphinetreatment while Cerezo observed up-regulation of PKC in hippocampus and limbic forebrain $(29,17)$. This may not be a contradiction as different areas were studied, different experimental conditions were given and the effect of posttranslational modification, e.g. phosphorylation for activation of PKC has to be considered. In agreement with the present study Prokai and coworkers demonstrated decreased levels of PKC using ICAT and LC/ESI-MS (19).

A multitude of steady state protein level changes following morphine have been shown, with some already reported and therefore a part can be considered confirmative. Many elements from different cascades and pathways, however, have never been described before in context with morphine administration and are presenting novel data.

Dysregulation of specific proteins may only point to deranged function and our findings encourage the study of functional proteomics and their functional effects when upor down-regulated. The biological meaning of altered levels may simply reflect or lead to pathophysiological phenomena of morphine administration. This proteomic approach to start a preliminary database of morphine-regulated proteins may also provide an analytical basis for scientists working in neuroproteomics in opiate systems. Further studies will show whether protein derangements are specific for morphine and whether the protein changes observed will turn out to be specific 'biomarkers'.

\section{Acknowledgements}

$\mathrm{AB}, \mathrm{JS}, \mathrm{JK}$ and TD were partially sponsored by grants from the Ministry of Science, Education and Sport in Poland (no. 3P04B 02024), and a grant from the International Centre for Genetic Engineering and Biotechnology, Trieste, Italy (no. CRP/POL05-02).

\section{References}

1. Oswald I: Human brain protein, drugs and dreams. Nature 223: 893-897, 1969.

2. Mackler SA and Eberwine JH: The molecular biology of addictive drugs. Mol Neurobiol 5: 45-58, 1991.

3. Harlan RE and Garcia MM: Drugs of abuse and immediateearly genes in the forebrain. Mol Neurobiol 16: 221-267, 1998.

4. Torres G and Horowitz JM: Drugs of abuse and brain gene expression. Psychosom Med 61: 630-650, 1999.

5. Ammon-Treiber S and Hollt V: Morphine-induced changes of gene expression in the brain. Addict Biol 10: 81-89, 2005.

6. Jacobs EH, Smit AB, de Vries TJ and Schoffelmeer AN: Longterm gene expression in the nucleus accumbens following heroin administration is subregion-specific and depends on the nature of drug administration. Addict Biol 10: 91-100, 2005.

7. Kim SY, Chudapongse N, Lee SM, Levin MC, Oh JT, Park HJ and Ho IK: Proteomic analysis of phosphotyrosyl proteins in morphine-dependent rat brains. Brain Res Mol Brain Res 133: 58-70, 2005

8. Fountoulakis M: Proteomics: current technologies and applications in neurological disorders and toxicology. Amino Acids 21: 363-381, 2001.

9. Yang JW, Czech T and Lubec G: Proteomic profiling of human hippocampus. Electrophoresis 25: 1169-1174, 2004.

10. Yang JW, Rodrigo R, Felipo V and Lubec G: Proteome analysis of primary neurons and astrocytes from rat cerebellum. J Proteome Res 4: 768-788, 2005.

11. Bodzon-Kulakowska A, Bierczynska-Krzysik A, Drabik A, Noga M, Kraj A, Suder P and Silberring J: Morphinome proteome of the nervous system after morphine treatment. Amino Acids 28: 13-19, 2005

12. Shin JH, Gulesserian T, Verger E, Delabar JM and Lubec G: Protein dysregulation in mouse hippocampus polytransgenic for chromosome 21 structures in the Down Syndrome Critical Region. J Proteome Res 5: 44-53, 2006.

13. Way EL, Loh HH and Shen FH: Simultaneous quantitative assessment of morphine tolerance and physical dependence. J Pharmacol Exp Ther 167: 1-8, 1969.

14. Yang JW, Suder P, Silberring J and Lubec G: Proteome analysis of mouse primary astrocytes. Neurochem Int 47: 159-172, 2005. 
15. Berndt $\mathrm{P}$, Hobohm $\mathrm{U}$ and Langen $\mathrm{H}$ : Reliable automatic protein identification from matrix-assisted laser desorption/ionization mass spectrometric peptide fingerprints. Electrophoresis 20: 3521-3526, 199.

16. Neer EJ, Schmidt CJ, Nambudripad R and Smith TF: The ancient regulatory-protein family of WD-repeat proteins. Nature 371: 297-300, 1994. Erratum in: Nature 371: 812, 1994.

17. Cerezo M, Milanes MV and Laorden ML: Alterations in protein kinase $\mathrm{A}$ and different protein kinase $\mathrm{C}$ isoforms in the heart during morphine withdrawal. Eur J Pharmacol 522: 9-19, 2005.

18. Lamb JR, Tugendreich S and Hieter P: Tetratrico peptide repeat interactions: to TPR or not to TPR? Trends Biochem Sci 20: 257-259, 1995.

19. Prokai L, Zharikova AD and Stevens SM Jr: Effect of chronic morphine exposure on the synaptic plasma-membrane subproteome of rats: a quantitative protein profiling study based on isotope-coded affinity tags and liquid chromatography/mass spectrometry. J Mass Spectrom 40: 169-175, 2005.

20. Vinnitskaia AG, Kurbat MN, Lelevich VV and Kozlovskii AV: GABA metabolism and contents of neuroactive amino acids in rat brain after acute morphine administration. Biomed Khim 51: 81-87, 2005.

21. Xi ZX and Stein EA: Increased mesolimbic GABA concentration blocks heroin self-administration in the rat. J Pharmacol Exp Ther 294: 613-619, 2000

22. Ellis EM and Hayes JD: Substrate specificity of an aflatoxinmetabolizing aldehyde reductase. Biochem J 312: 535-541, 1995.

23. Sarti P, Giuffre A, Barone MC, Forte E, Mastronicola D and Brunori M: Nitric oxide and cytochrome oxidase: reaction mechanisms from the enzyme to the cell. Free Radic Biol Med 34: 509-520, 2003.

24. Di Francesco P, Tavazzi B, Gaziano R, Lazzarino G, Casalinuovo IA, Di Pierro D and Garaci E: Differential effects of acute morphine administrations on polymorphonuclear cell metabolism in various mouse strains. Life Sci 63: 2167-2174, 1998.

25. Banfield MJ, Barker JJ, Perry AC and Brady RL: Function from structure? The crystal structure of human phosphatidylethanolamine-binding protein suggests a role in membrane signal transduction. Structure 6: 1245-1254, 1998.

26. George AJ, Holsinger RM, McLean CA, Tan SS, Scott HS, Cardamone T, Cappai R, Masters CL and Li QX: Decreased phosphatidylethanolamine binding protein expression correlates with $A B$ accumulation in the Tg2576 mouse model of Alzheimer's disease. Neurobiol Aging 27: 614-623, 2006.

27. Wahba ZZ, Oriaku ET and Soliman KF: Brain cholinergic involvement during the rapid development of tolerance to morphine. Pharmacology 34: 66-73, 1987.

28. Hartl FU and Martin J: Molecular chaperones in cellular protein folding. Curr Opin Struct Biol 5: 92-102, 1995.

29. Li Y, Eitan S, Wu J, Evans CJ, Kieffer B, Sun X and Polakiewicz RD: Morphine induces desensitization of insulin receptor signaling. Mol Cell Biol 23: 6255-6266, 2003.

30. Naassila M, Pierrefiche O, Beauge FJ, Sebire N and Daoust M: Chronic ethanol exposure differentially regulates NOS1 mRNA levels depending on rat brain area. Neurosci Lett 338: 221-224, 2003.
31. Muller DL and Unterwald EM: D1 dopamine receptors modulate deltaFosB induction in rat striatum after intermittent morphine administration. J Pharmacol Exp Ther 314: 148-154, 2005.

32. Bota DA, Ngo JK and Davies KJ: Downregulation of the human Lon protease impairs mitochondrial structure and function and causes cell death. Free Radic Biol Med 38: 665-677, 2005.

33. Mao J, Sung B, Ji RR and Lim G: Neuronal apoptosis associated with morphine tolerance: evidence for an opioid-induced neurotoxic mechanism. J Neurosci 22: 7650-7661, 2002.

34. Lim G, Wang S, Lim JA and Mao J: Activity of adenylyl cyclase and protein kinase A contributes to morphine-induced spinal apoptosis. Neurosci Lett 389: 104-108, 2005.

35. Ela C, Hasin Y and Eilam Y: Opioid effects on contractility, $\mathrm{Ca}(2+)$-transients and intracellular $\mathrm{pH}$ in cultured cardiac myocytes. J Mol Cell Cardiol 25: 599-613, 1993.

36. Campillos M, Lamas JR, Garcia MA, Bullido MJ, Valdivieso F and Vazquez J: Specific interaction of heterogeneous nuclear ribonucleoprotein A1 with the $-219 \mathrm{~T}$ allelic form modulates APOE promoter activity. Nucleic Acids Res 31: 3063-3070, 2003.

37. Ziolkowska B, Urbanski MJ, Wawrzczak-Bargiela A, Bilecki W and Przewlocki R: Morphine activates Arc expression in the mouse striatum and in mouse neuroblastoma Neuro2A MOR1A cells expressing mu-opioid receptors. J Neurosci Res 82: 563-570, 2005.

38. Zhou JF, Yan XF, Ruan ZR, Peng FY, Cai D, Yuan H, Sun L, Ding DY and Xu SS: Heroin abuse and nitric oxide, oxidation, peroxidation, lipoperoxidation. Biomed Environ Sci 13: 131-139, 2000.

39. Beeckmans S, Van Driessche E and Kanarek L: Clustering of sequential enzymes in the glycolytic pathway and the citric acid cycle. J Cell Biochem 43: 297-306, 1990.

40. Eber SW, Pekrun A, Bardosi A, Gahr M, Krietsch WK, Kruger J, Matthei R and Schroter W: Triosephosphate isomerase deficiency: haemolytic anaemia, myopathy with altered mitochondria and mental retardation due to a new variant with accelerated enzyme catabolism and diminished specific activity. Eur J Pediatr 150: 761-766, 1991

41. Mkrtchian S, Fang C, Hellman U and Ingelman-Sundberg M: A stress-inducible rat liver endoplasmic reticulum protein, ERp29. Eur J Biochem 251: 304-313, 1998.

42. Ammon-Treiber S, Grecksch G, Stumm R, Riechert U, Tischmeyer H, Reichenauer A and Hollt V: Rapid, transient, and dose-dependent expression of hsp70 messenger RNA in the rat brain after morphine treatment. Cell Stress Chaperones 9: 182-197, 2004.

43. Mouledous L, Neasta J, Uttenweiler-Joseph S, Stella A, Matondo M, Corbani M, Monsarrat B and Meunier JC: Longterm morphine treatment enhances proteasome-dependent degradation of G $\beta$ in human neuroblastoma SH-SY5Y cells: correlation with onset of adenylate cyclase sensitization. Mol Pharmacol 68: 467-476, 2005.

44. Liu JG and Anand KJ: Protein kinases modulate the cellular adaptations associated with opioid tolerance and dependence. Brain Res Brain Res Rev 38: 1-19, 2001.

Supplementary Table II. A brief description of cerebral cortex, hippocampus and striatum proteins identified in morphine dependence.

\begin{tabular}{lll}
\hline Brain structure $\quad$ Protein name & $\begin{array}{l}\text { Relative protein content } \\
\text { (dependence vs. control) }\end{array}$ & Protein function
\end{tabular}

Cerebral cortex Similar to isoform of WD-repeat protein 1 (O88342) Mouse (98\% identity), (syn hypothetical LOC360950)

Translocase of outer mitochondrial membrane 70 homolog A
Transmembrane signaling, transcription regulation, cell division, cell-fate determination, mRNA modification, vesicle fusion and apoptosis

up-regulated Cell-cycle regulation, transcription repression, stress response, protein folding, protein kinase inhibition, neurogenesis and mitochondrial and preoxisomal protein transport

Participates in the citric acid cycle and catalyses the interconversion of malate to oxaloacetate 
Supplementary Table II. Continued.

\begin{tabular}{ll}
\hline Brain structure $\quad$ Protein name & $\begin{array}{l}\text { Relative protein content } \\
\text { (dependence vs. control) }\end{array}$
\end{tabular}
4-aminobutyrate aminotransferase,
mitochondrial (Precursor)

Aldo-keto reductase family 7 , member A2

Cytochrome c oxidase polypeptide $\mathrm{Vb}$, mitochondrial (Precursor)

ATP synthase $\beta$ chain, mitochondrial (Precursor)

Phosphatidylethanolamine-binding protein

Hippocampus Heat shock cognate $71 \mathrm{kDa}$ protein

Aldose 1-epimerase

Septin-6

Lon protease

Striatum

L-lactate dehydrogenase B chain

F-actin capping protein $\beta$ subunit

ATPase, $\mathrm{H}^{+}$transporting, V1 subunit A, isoform 1

Dynamin 1-like protein

Protein kinase $\mathrm{C}$ and casein kinase substrate in neurons protein 1

3-mercaptopyruvate sulfurtransferase

Endoplasmic reticulum protein ERp29

(Precursor)

Superoxide dismutase ( $\mathrm{Cu}-\mathrm{Zn})$ down-regulated

Metabolic degradation of GABA

down-regulated

down-regulated

down-regulated

down-regulated

up-regulated

up-regulated

down-regulated

down-regulated

up-regulated

up-regulated

up-regulated

up-regulated

down-regulated

down-regulated

down-regulated

down-regulated to alcohols cytochrome $\mathrm{c}$ to oxygen nervous system brain neuropeptide maltose and lactose neurological disorders glycolysis

Binds actin compartments in eukaryotic cells Regulates membrane fission compounds thiosulfate biosynthesis
Catalyzes the reduction of toxic aldehydes, including $\alpha$-unsaturated carbonyl compounds,

Involved in the transfer of electrons from

Produces ATP from ADP in the presence of a proton gradient across the membrane

Binds ATP, opioids and phosphatidylethanolamine, increases the production of choline acetyltransferasen and may be involved in the function of the presynaptic cholinergic neurons of the central

Interacts with the cell-signaling machinery, functions as a precursor protein of a bioactive

Involved in protein folding and refolding

Converts $\alpha$-aldose to the $\beta$-anomer; it is active on D-glucose, L-arabinose, D-xylose, D-galactose,

Associated with cytokinesis and exocytosis, along with contributing to the development of

Considered to play a general role in cellular morphogenesis and functions involving specialized regions of the cell cortex and changes in cell shape

Regulates multiple mitochondrial functions, may act as a chaperone, independent of its proteolytic activity

Metabolic enzyme which catalyses the conversion of L-lactate to pyruvate, the last step in anaerobic

Is involved in processes such as cell movement phagocytosis and muscle contraction

Responsible for acidifying a variety of intracellular

Plays a role on organelles of the secretory pathway

Hydrolyzes GTP oligomerizing to form ring-like structures, may remodel membranes

Plays a role in clathrin-mediated endocytosis, apoptosis, vesicle transport, cell signalling, morphogenesis and transcriptional regulation

Transfers a sulfur ion to cyanide or to other thiol

May play a role in cyanide degradation or in

Plays an important role in the processing of secretory proteins within the endoplasmic reticulum

Response to oxidative stress and removal of superoxide radicals

Destroys radicals which are normally produced within the cells and which are toxic to biological systems 
Supplementary Table II. Continued.

\begin{tabular}{|c|c|c|c|}
\hline Brain structure & Protein name & $\begin{array}{l}\text { Relative protein content } \\
\text { (dependence vs. control) }\end{array}$ & Protein function \\
\hline & Hnrpa1 protein & down-regulated & $\begin{array}{l}\text { Nucleotide binding } \\
\text { RNA binding }\end{array}$ \\
\hline & $\begin{array}{l}\text { ATP synthase } \alpha \text { chain, mitochondrial } \\
\text { (Precursor) (Fragment) }\end{array}$ & down-regulated & Binds ATP \\
\hline & Proteasome subunit $\beta$ type 7 (Precursor) & down-regulated & $\begin{array}{l}\text { Degrades abnormal, short-lived and regulatory } \\
\text { proteins } \\
\text { Controls cellular processes, metabolism and the } \\
\text { cell cycle }\end{array}$ \\
\hline & Triosephosphate isomerase & down-regulated & $\begin{array}{l}\text { Plays an important role in several metabolic } \\
\text { pathways and is essential for efficient energy } \\
\text { production }\end{array}$ \\
\hline & $\begin{array}{l}\text { [Pyruvate dehydrogenase (Lipoamide)]- } \\
\text { phosphatase } 1, \text { mitochondrial (Precursor) }\end{array}$ & down-regulated & $\begin{array}{l}\text { Catalyzes the dephosphorylation and concomitant } \\
\text { reactivation of the } \alpha \text { subunit of the E } 1 \text { component of } \\
\text { the pyruvate dehydrogenase complex } \\
\text { Plays a key role in regulation of neuronal activity and } \\
\text { stress signaling pathway }\end{array}$ \\
\hline
\end{tabular}
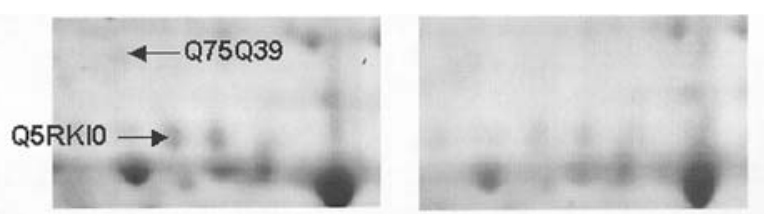

Supplementary Figure 1. Spots representing up-regulated proteins in the cerebral cortex of morphine-dependent rat (left) vs. control sample (right).

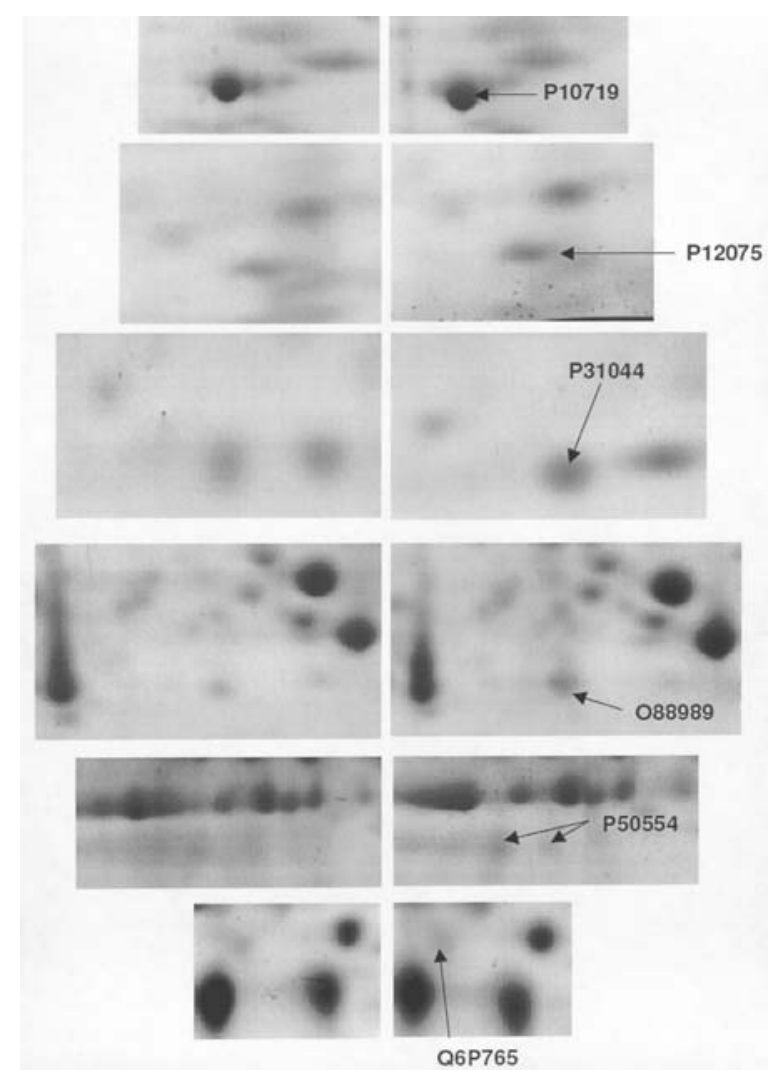

Supplementary Figure 2. Spots representing down-regulated proteins in the cerebral cortex of morphine-dependent rat (left) vs. control sample (right).

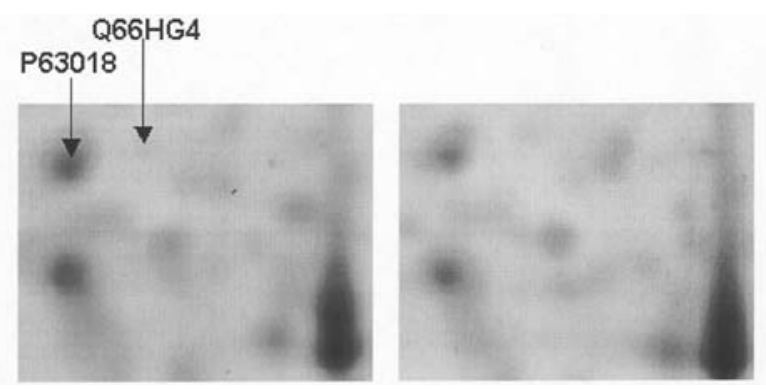

Figure 3. Spots representing up-regulated proteins in hippocampus of morphine-dependent rat (left) vs. control sample (right).
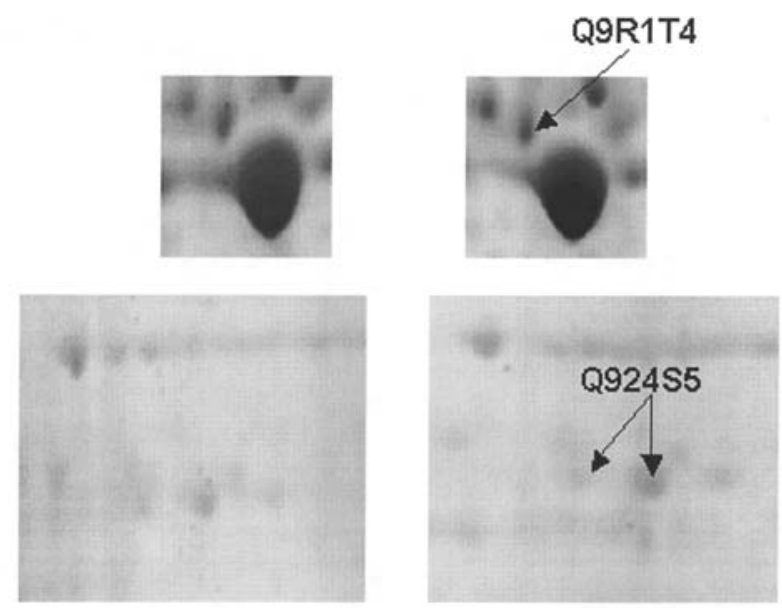

Figure 4. Spots representing down-regulated proteins in hippocampus of morphine-dependent rat (left) vs. control sample (right). 

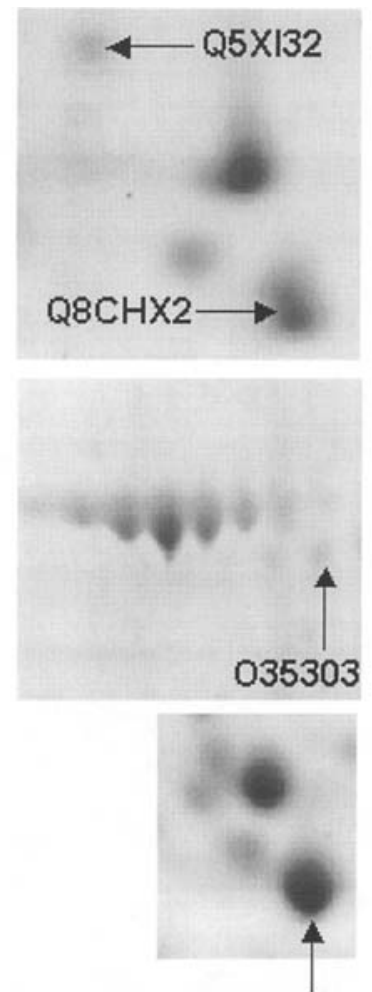

$\mathrm{P} 42123$

Figure 5. Spots representing up-regulated proteins in the striatum of morphine-dependent rat (left) vs. control sample (right).

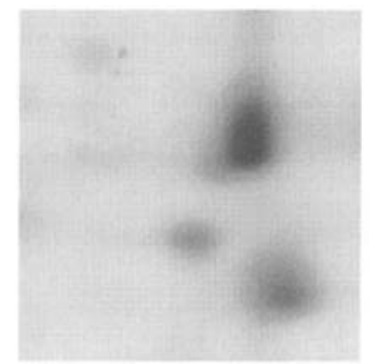

,

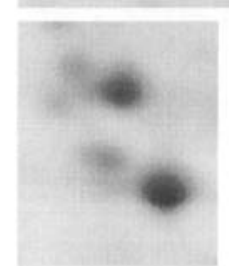

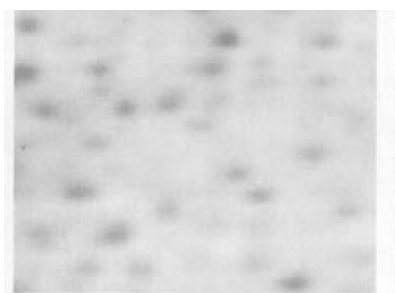
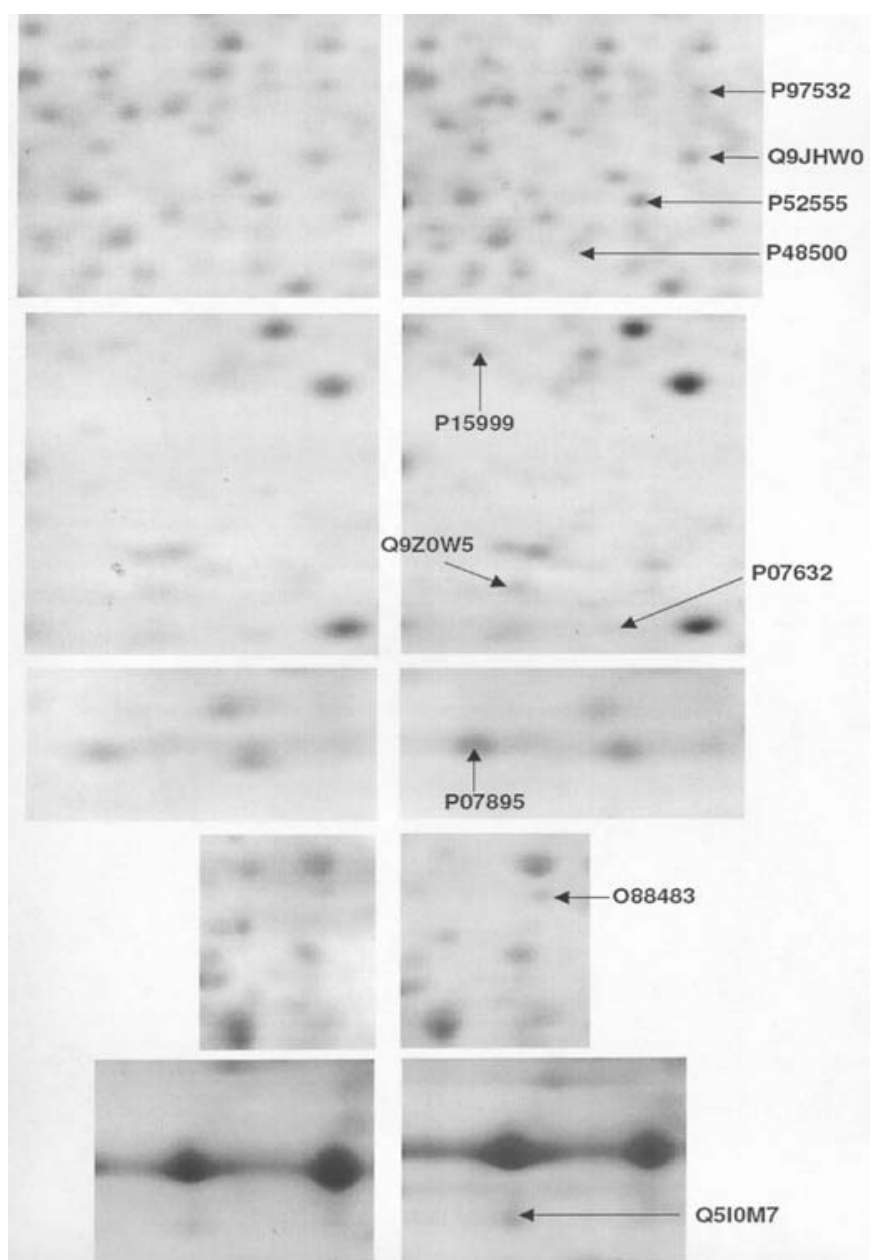

Figure 6. Spots representing down-regulated proteins in the striatum of morphine-dependent rat (left) vs. control sample (right). 